\title{
The Level of Physical Activity, Lung Function and Exercise Capacity of Children and Adolescents With Cystic Fibrosis Compared to Healthy Controls
}

\section{Marjane Cardoso}

Universidade Federal do Rio Grande do Sul

Caroline Jacoby Schmidt

Universidade Federal do Rio Grande do Sul https://orcid.org/0000-0002-7971-3366

\section{Gabriela Motter}

Universidade Federal do Rio Grande do Sul

\section{Gabrielle Costa Borba}

Universidade Federal do Rio Grande do Sul

\section{Tatiana Helena Rech}

Universidade Federal do Rio Grande do Sul

\section{Paulo José Cauduro Marostica}

Universidade Federal do Rio Grande do Sul

\section{Paula Maria Eidt Rovedder ( $\nabla$ provedder@hcpa.edu.br)}

Universidade Federal do Rio Grande do Sul https://orcid.org/0000-0003-1695-0820

Research article

Keywords: Cystic Fibrosis, children, Physical Activity

Posted Date: April 7th, 2020

DOl: https://doi.org/10.21203/rs.3.rs-20362/v1

License: (9) This work is licensed under a Creative Commons Attribution 4.0 International License.

Read Full License 


\section{Abstract}

Background : people with Cystic Fibrosis (CF) have progressive limitation to physical exercise and reduced daily living activities. Regular physical activity (PA) and exercise contribute to the quality of live of people with CF. The objective of this study was to evaluate level of PA, lung function and functional capacity in children and adolescents diagnosed with $\mathrm{CF}$ and compare them with those of healthy children and adolescents.

Methodology: the study had a cross-sectional design with a control group. Patients with CF were followed at the Children's Pneumology Outpatient Clinic, and were matched for age and sex with healthy controls from a local public school. The evaluations included daily step count, the shuttle walk test and spirometry.

Results: 70 children and adolescents were evaluated, 35 diagnosed with CF and 35 healthy controls. The overall mean age was $11.6 \pm 2.9$ years. There was no significant difference in level of PA between the patient and control groups. Gender analysis revealed no significant difference in level of PA between the groups or within the CF group. The CF group values were significantly lower than the control group for $\operatorname{BMI}(p=0.04)$, percentage of predicted FEV 1 and FEV 1 Z-score $(p=0.02$ and $p=0.010)$.

Conclusion: In this sample, children and adolescents with CF had the same level of PA as their healthy peers. Boys and girls with CF had similar level of PA when stratified by sex, as well as when compared to healthy peers of the same gender. Differences were observed between BMI, FEV 1 and some functional capacity test variables between the groups.

\section{Introduction}

Cystic fibrosis (CF) is a genetic disease with an autosomal recessive inheritance pattern that is more common among caucasians. Its clinical manifestations and symptom severity can vary considerably from one patient to another ${ }^{(1)}$.

People with CF frequently present progressive limitations in physical exercise capacity and reduced activities of daily living. The main causes of exercise intolerance involve reduced ventilatory capacity and reserve, loss of peripheral skeletal muscle mass and decreased cardiovascular function ${ }^{(2,3)}$.

Due to the progressive loss of lung function and exercise capacity in this population, regular physical activity (PA) has been an adjunct to treatment, since it has been associated with improved prognosis, delayed pulmonary function decline, increased survival and improved quality of life in these people ${ }^{(4,5)}$. Regular PA and exercise are factors that contribute to the quality of life of CF patients, and a progressive decrease in exercise may also reflect a decrease in daily PA in children with $\mathrm{CF}^{(4)}$.

The literature has demonstrated ways of assessing PA in healthy children with specific devices such as pedometers, which are low cost, easy to handle and have adequate safety and reliability ${ }^{(6)}$. Pedometer 
and accelerometer have a moderate to strong correlation for activity level classification. It is important to emphasize that these devices evaluate different results, accelerometer detects PA intensity, while the pedometer identifies less active children ${ }^{(7,8)}$. A recent study with healthy children and adolescents estimated the number of steps they took per day to ensure moderate PA in this population. Twelve thousand steps per day for girls and 15000 steps per day for boys were considered a suitable level of PA for these children and adolescents ${ }^{(9)}$.

In clinical practice, there is a need to quantify the PA of children and adolescents with CF to allow evaluation and monitoring of PA so that exercise-related interventions can be developed for this population. Therefore, the objective of this study was to evaluate level of PA, lung function and functional capacity in children and adolescents diagnosed with $\mathrm{CF}$ and compare them with those of healthy children and adolescents.

\section{Methods}

The study design was cross-sectional and included a control group of healthy children and adolescents. The study protocol was approved by the Ethics Committee of the Hospital de Clínicas de Porto Alegre (HCPA), and free and informed consent was obtained from each participant's parents or guardians (150143/2015).

Seventy children and adolescents, $35 \mathrm{CF}$ people and 35 healthy controls matched for age and sex, were included in the study. The patients aged 6 to 18 years who had been diagnosed with CF according to European Consensus criteria ${ }^{(10)}$ and were being followed up at the HCPA Child Pneumology Clinic. Exclusion criteria included parent or guardian refusal to participate, heart disease, motor impairment, cognitive disability or another clinical condition that prevented taking the involved tests.

The control group consisted of healthy children and adolescents matched with the CF group by age and sex. The children's health was previously determined using a simple questionnaire answered by a parent or guardian, and was defined as able to take the proposed tests, no previous history of respiratory disease, cardiac disease or motor impairment, a body mass index $(\mathrm{BMI})<25 \mathrm{~kg} / \mathrm{m}^{2}$ and normal spirometric values. Those in the control group, who were recruited from a public school in Porto Alegre, agreed to participate in the study and their parents or guardians signed the free and informed consent form.

The evaluations included: the use of a pedometer to count the number of steps taken daily for sevendays, the shuttle walk test, and spirometry. All tests were performed within a maximum of one week. Both groups were questioned if they performed PA, which we consider to be regular PA according to the World Health Organization ${ }^{(11)}$.

\section{Level of Daily Physical Activity}


The level of PA was evaluated using a movement sensor known as a pedometer, which records the body's vertical oscillations and indicates the number of steps taken by the user. The pedometer (Yamax, Digi Walker SW 700, Tokyo, Japan) used for the study was selected because previous studies have shown it to be more reliable for assessing PA in children and they record the number of steps taken daily $(7,12)$. The use of a pedometer to evaluate PA is due to its low cost, as devices such as accelerometers are considerably expensive, which makes it difficult to use in studies with limited financial resources.

The CF children, along with their parents or guardians, received pedometer training on orientation day. The healthy controls received the same training as the CF group; controls under 10 years old were trained in the presence of a parent or guardian. All participants were instructed to wear the pedometer for seven consecutive days, being at least five days to be accepted for the study, with the device positioned at the waist near the anterior iliac crest, and that it could only be removed to bathe or sleep. The participants recorded the daily number of steps taken on each of the seven days on a form provided by the researchers. They were also given a document on pedometer use and management and were instructed to maintain their normal routines of PA. The CF group received the device on the consultation day and after use as protocol, the device is returned on routine consultation, the healthy control group received the device on the researcher's visit to school and returned the device after use. A researcher also made phone contact with all participants during the recording period. Telephone contact was made in two moments: between the first and third day of use, to ask questions and make sure that the children was using it correctly, and at the end of the week of use, to find out if they had completed the use of seven days.

The participants' level of PA were classified according to Craig et al. ${ }^{(9)}$, which considers the number of steps per day according to age group and gender. The two highest weekday values (Monday through Friday) and the highest weekend value (Saturday or Sunday) were selected for analysis to predict weekly $\mathrm{PA}^{(13)}$. The mean number of steps per day was calculated from the sum of the steps taken on these three days, and the daily physical activity was then classified as light, mild moderate, moderate, moderate to vigorous end vigorous ${ }^{(9)}$.

\section{Shuttle Walk Test}

The SWT was performed according to Singh et al. ${ }^{(14)}$. The test consists of 12 levels of increasing speed controlled by sound signals in a flat $10 \mathrm{~m}$ corridor, which is marked using two cones. The maximum test time is $12 \mathrm{~min}$ and the maximum distance covered is $1020 \mathrm{~m}$. The variables distance in meters, test execution time (in minutes), heart rate (HR), respiratory rate (RR), blood pressure, peripheral oxygen saturation (Sp02) and a modified Borg scale $\mathrm{e}^{(15)}$.

\section{Pulmonary Function Test}

Spirometry was performed in the CF group with a spirometer (MasterScreen, v4.31, Jaeger, Würzburg, Germany) and in the control group with a portable device (Sibelmed, Dato Spir C, Barcelona, Spain) ${ }^{(16)}$. Forced vital capacity (FVC) and forced expiratory volume in the first second (FEV $)_{1}$ were recorded. All 
parameters were expressed in absolute values and in percentage of the predicted value for age, height and sex ${ }^{(17)}$. The Z-scores for FVC and $\mathrm{FEV}_{1}$ were calculated ${ }^{(18)}$.

\section{Clinical Score}

The Shwachman and Kulczycki clinical score ${ }^{(19)}$ was used for clinical evaluation of the patients. It involves four different aspects: general activity, nutrition, a physical examination and thoracic radiological findings. Each aspect was scored on a scale of 5 to 25 points; a final score of 100 points represents the best possible clinical condition ${ }^{(19)}$.

\section{Statistical Analysis}

The data were expressed as the number of cases (proportion), mean \pm SD or median (interquartile range). Comparisons between categorical variables were performed using the chi-square test with adjusted standardized residuals, applying the Yates correction or Fisher's exact test when indicated. The $t$-test for independent samples was used to compare continuous variables with normal distribution between the two groups. The Mann-Whitney $U$ test was used to compare ordinal variables or continuous variables without normal distribution.

The data were analyzed using SPSS version 22.0. The level of statistical significance was set at $p<0.05$. All statistical tests used were two-tailed ${ }^{(20)}$.

\section{Results}

Besides the $35 \mathrm{CF}$ people included in the study, five others were excluded for the following reasons: two experienced pulmonary exacerbation during the test period, two refused to participate, and one had heart failure. The mean participant age was $11.6 \pm 2.9$ years and 91\% reported regular physical activity. Table 1 presents the general characteristics of the patient and control groups. The CF group had significantly lower absolute BMI values $(p=0.004)$, percentage of predicted $\mathrm{FEV}_{1}$, and $\mathrm{FEV}_{1}$ Z-scores $(\mathrm{p}=0.002$ and $\mathrm{p}=0.010$, respectively) than the control group.

Table 1 - Comparison of the general characteristics between the patient and control groups 


\begin{tabular}{|c|c|c|c|}
\hline Variables & $\begin{array}{l}\text { Patients } \\
(\mathrm{n}=35)\end{array}$ & $\begin{array}{l}\text { Controls } \\
(n=35)\end{array}$ & $\bar{P}$ \\
\hline Age $^{\mathrm{a}}$ (years) & $11.5 \pm 3.1$ & $11.7 \pm 2.8$ & 0.378 \\
\hline Gender $^{b}$ (male/female) & $14 / 21$ & $14 / 21$ & 0.596 \\
\hline Absolute BMI ${ }^{\mathrm{a}}(\mathrm{Kg} / \mathrm{m} \square)$ & $18.2 \pm 2.2$ & $19.1 \pm 3.6$ & 0.004 \\
\hline BMI Percentile $^{a}$ & $47.9 \pm 26.0$ & $57.2 \pm 30.9$ & 0.176 \\
\hline BMI Z-Score & $-0.08 \pm 0.8$ & $0.24 \pm 1.1$ & 0.070 \\
\hline $\mathrm{FEV}_{1}^{\mathrm{a}}$ (\% predicted) & $83.3 \pm 19.4$ & $87.6 \pm 10.6$ & 0.002 \\
\hline $\mathrm{FEV}_{1} \mathrm{Z}$-Score & $-1.4 \pm 1.6$ & $-0.9 \pm 1.0$ & 0.010 \\
\hline $\mathrm{FVC}^{\mathrm{a}}$ (\% predicted) & $93.5 \pm 18.5$ & $96.6 \pm 12.9$ & 0.059 \\
\hline FVC Z-Score & $-0.5 \pm 1.6$ & $-0.2 \pm 1.0$ & 0.043 \\
\hline S-K Clinical Score ${ }^{\mathrm{C}}$ & $85(80-90)$ & - & - \\
\hline
\end{tabular}

${ }^{a}$ Values expressed as mean $\pm \mathrm{SD}$. ${ }^{b}$ Values expressed in number of cases. ${ }^{\mathrm{C}}$ Values expressed in median $\left(25^{\text {th }}\right.$ percentile/ $75^{\text {th }}$ percentile). BMI = body mass index; $\mathrm{FEV}_{1}=$ forced expiratory volume in the first second; FVC = forced vital capacity; S-K Clinical Score = Shwachman and Kulczycki; Chi-square test for categorical variables; $t$-test for independent samples for continuous variables with normal distribution.

Table 2 compares level of PA and the main variables of the submaximal exercise capacity tests between the CF and control groups. There was no difference in level of PA between groups according to the average number of steps on weekdays, weekends, the three most active days and the seven total days ( $p>0.05)$. According to the modified Borg scale $^{(13)}$, the CF group had significantly lower dyspnea values at the end of the SWT than the control group $(p=0.036)$.

Table 2 - Comparison of the level of daily physical activity and shuttle walk test between two groups 


\begin{tabular}{|c|c|c|c|}
\hline Variables & $\begin{array}{l}\text { Patient } \\
(\mathrm{n}=35)\end{array}$ & $\begin{array}{l}\text { Control } \\
(\mathrm{n}=35)\end{array}$ & $\mathrm{p}$ \\
\hline Number of steps ${ }^{\text {a }}$ (weekdays) & $9752 \pm 3.922$ & $8685 \pm 3.239$ & 0.223 \\
\hline Number of steps ${ }^{\mathrm{a}}$ (weekend) & $8937 \pm 3.908$ & $8092 \pm 5603$ & 0.434 \\
\hline Number of steps (3 most active days) & $11535 \pm 4150$ & $10610 \pm 4481$ & 0.371 \\
\hline $\begin{array}{l}\text { Number of steps a (total - } 7 \text { days) } \\
\text { Shuttle walk test }\end{array}$ & $9519 \pm 3658$ & $8515 \pm 3.679$ & 0.240 \\
\hline $\begin{array}{l}\text { Distance (meters) } \\
\text { Time (minutes) }\end{array}$ & $\begin{array}{c}803.1 \pm 197.9 \\
10.5 \pm 1.4\end{array}$ & $\begin{array}{c}786.3 \pm 211.3 \\
10.2 \pm 1.7\end{array}$ & $\begin{array}{l}0.688 \\
0.487\end{array}$ \\
\hline $\mathrm{SpO}_{2}$ (resting) & $97.9 \pm 1.8$ & $98.5 \pm 1.0$ & 0.088 \\
\hline $\mathrm{SpO}_{2}$ (end of test) & $97.9 \pm 1.7$ & $98.4 \pm 1.4$ & 0.123 \\
\hline $\begin{array}{l}\text { Borg D (resting) } \\
\text { Borg D (end of test) } \\
\text { Borg F resting } \\
\text { Borg F (end of test) }\end{array}$ & $\begin{array}{l}0.1 \pm 0.2 \\
2.3 \pm 2.4 \\
0.2 \pm 0.6 \\
2.4 \pm 2.6\end{array}$ & $\begin{array}{l}0.2 \pm 0.3 \\
3.4 \pm 2.5 \\
0.3 \pm 0.8 \\
3.4 \pm 2.7\end{array}$ & $\begin{array}{r}0.088 \\
0.036 \\
0.644 \\
0.131\end{array}$ \\
\hline Physical Activity ${ }^{\mathrm{C}}(\%$ yes) & $91.4 \%$ & $65.7 \%$ & 0.816 \\
\hline
\end{tabular}

${ }^{\text {a }}$ Values expressed as mean $\pm \mathrm{SD}$. ${ }^{\mathrm{b}}$ Values expressed in number of cases. ${ }^{\mathrm{C}}$ Values expressed as a percentage. $\mathrm{SpO}_{2}=$ Peripheral oxygen saturation; Borg $\mathrm{D}=$ dyspnea perception scale; Borg $\mathrm{F}=$ lower limb fatigue scale. $T$-test for independent samples. Mann-Whitney U Test.

There was no significant difference between CF and control group level of PA scores for the mean number of steps on the most active days $(\mathrm{p}=0.350)$, Table 3 .

Table 3 - Comparison of the classification of daily physical activity levels between the patient and control groups

\begin{tabular}{lcccc}
\hline LDPA Classification & $\begin{array}{c}\text { Total } \\
(\mathrm{n}=70)\end{array}$ & $\begin{array}{c}\text { Patient } \\
(\mathrm{n}=35)\end{array}$ & $\begin{array}{c}\text { Control } \\
(\mathrm{n}=35)\end{array}$ & $\mathrm{p}$ \\
\hline & & & & \\
Vigorous n (\%) & $15(21.4)$ & $9(25.7)$ & $6(17.1)$ & \\
Moderate - vigorous n (\%) & $16(22.9)$ & $11(31.4)$ & $5(14.3)$ & \\
Moderate n (\%) & $12(17.1)$ & $3(8.6)$ & $9(25.7)$ & 0.350 \\
Mild - moderate n (\%) & $12(17.1)$ & $7(20)$ & $5(14.3)$ & \\
Light n (\%) & $15(21.4)$ & $5(14.3)$ & $10(28.6)$ & \\
\hline
\end{tabular}

Values expressed in number of cases and percentage. LDPA = daily physical activity level. Mann-Whitney U Test. 
The figures 1 and 2 show the sex-stratified level of PA analysis in the CF and control groups and in the CF group alone, respectively. There was no significant difference in level of PA in relation to $\operatorname{sex}(\mathrm{p}=0.05)$.

Figure 1. Comparison of level of daily physical activity stratified by gender in the patient and control groups.

Figure 2. Comparison of level of daily physical activity between genders in CF patients.

\section{Discussion}

The results of the present study demonstrated that children and adolescents with CF have the same level of PA as healthy children and adolescents. There were no differences between the level of PA of girls and boys within the CF group or between the CF and control groups. In the functional capacity tests, the control group had higher values on the perception of dyspnea and lower limb fatigue scales. The 7-day step count results indicated that the level of PA of the CF group was not different from that of the healthy group. The mean number of steps in this study was 9,519 and 8,515 per day for the control and CF groups, respectively. A recent study evaluated a pedometer's ease of use by assessing the level of PA of $30 \mathrm{CF}$ people who had a mean age of $22 \pm 7$ and an $\mathrm{FEV}_{1}$ of $57 \pm 25 \%$. The study found a mean of 6,000 steps per day, which is $50 \%$ lower than values reported in the literature for healthy adolescents and young adults $^{(8)}$. The expected number of steps per day for these healthy individuals was between 9,000 and 13,000 , depending on age and sex ${ }^{(8,21)}$. There are multifactorial reasons that may influence level of PA reduction in individuals with $\mathrm{CF}$, particularly decreased pulmonary function, poor nutritional status, skeletal muscle dysfunction, and respiratory symptoms ${ }^{(22-24)}$. The level of PA of both the CF group and the healthy group were comparable to the findings of these studies. Our subjects had preserved lung function ( $\mathrm{FEV}_{1} 83.3 \pm 19.4 \%$ ), 91.4\% got regular exercise ${ }^{(11)}$, and 23 of 35 were classified as having moderate to vigorous level of PA. Our subjects are encouraged at each outpatient visit to get regular exercise, which may have influenced their good level of PA.

One study involving another type of level of PA measurement device (an accelerometer) that compared healthy children and children with $\mathrm{CF}$ found very similar results to ours, including a lower percentage of predicted $\mathrm{FEV}_{1} \%$ and similar level of PA between groups $^{(25)}$.

A systematic review established minimum recommendations for level of PA based on the number of steps per day and the age range of healthy children and adolescents ${ }^{(26)}: 13,000$ to 15,000 for pre-school children, 11,000 and 12,000 for girls and boys (aged 7 to 12 years), respectively; and 10,000 to 11,700 for adolescents. Similar step counts were established for boys and girls in the preschool and adolescent stages, in contrast to the school stage (7 to 12 years) in which the boys are more active than the girls. In our study, however, we observed no significant difference in the number of steps between boys and girls 
or within the CF group. Since our participants had a mean age of 11 years (6 to 17 years), our hypothesis is that the small sample size might not have been able to demonstrate the expected difference.

Musculoskeletal dysfunction and nutritional status could interfere with the physical performance and daily activity of individuals with $\mathrm{CF}^{(2)}$. The $\mathrm{CF}$ group presented significantly lower values in absolute BMI than the control group. However, the difference in values did not have sufficient clinical relevance to interfere with the group's level of PA. In addition, the CF group's BMI was in the adequate range and the BMI percentile and Z-scores did not differ between groups.

Decreased lung function in CF people may lead to decreased exercise tolerance, lower performance in daily activities, and dyspnea(10). According to Prasad and Cerny ${ }^{(27)}$, CF people with $\mathrm{FEV}_{1}$ values $>55 \%$ of predicted in pulmonary function tests can exercise at the same intensity as healthy individuals. In our study, although the CF group presented significantly lower FEV ${ }_{1}$ Z-scores than the control group, they were still within normality, i.e., they did not characterize any degree of ventilatory disorder. Thus, we considered that this finding could not lower the CF people's level of PA.

Functional tests assess exercise tolerance and are widely used in individuals with respiratory disease. The SWT is considered a submaximal exercise test, demanding an ever greater physical effort from the individual, since it involves progressive speed levels ${ }^{(14)}$. Our results for this test showed no difference in distance covered or time of execution between groups. The control group had higher perceived dyspnea values on the modified Borg scale ${ }^{(15)}$ at the end of the test than the CF group, This may demonstrate that children with CF are more apt to PA than their healthy controls, as found in the study by Selvadurai et al where CF children, until puberty, were more active than their healthy controls ${ }^{(28)}$. It could be that the control group was not as accustomed to this scale as the $\mathrm{CF}$, who routinely perform functional tests; we also consider that a modified Borg scale ${ }^{(15)}$ may not be the best instrument for assessing dyspnea in younger children due to comprehension difficulties ${ }^{(15)}$.

The present study has some limitations. The gold standard for exercise evaluation, cardiopulmonary exercise testing that measures maximum oxygen consumption, was not used to measure aerobic condition, which may have influenced sensitivity to aerobic variation in the participants. Nevertheless, the control group served to minimize this limitation and led to a clearer evaluation of the CF patients.

The clinical implications of the present study involve the importance incentive programs to increase PA in the community should be established and not just for young people with CF. In addition, although CF is an exercise-limiting disease, implementing routine physical activity has caused young people with $\mathrm{CF}$ to achieve such similar results when compared to young people without the disease. The study can broaden the current recommendations of exercise and contribute to CF patients and family interventions.

\section{Conclusion}


In conclusion, we found that children and adolescents with CF have the same level of PA as healthy controls of the same age and gender. There was no difference in level of PA between boys and girls within the CF group or between the CF and healthy groups. Differences were observed in $\mathrm{BMI} \mathrm{FEV}_{1}$ and some functional capacity test variables between the CF and control groups, although they were not significant.

\section{List Of Abbreviations}

BMI - Body mass index

CF - Cystic fibrosis

$\mathrm{FEV}_{1}$ - Forced expiratory volume in the first second

FVC - Forced vital capacity

HCPA - Hospital de Clínicas de Porto Alegre

HR - Heart rate

PA - Physical activity

RR - Respiratory rate

Sp02 - Peripheral oxygen saturation

SWT - Shuttle Walk Test

\section{Declarations}

Ethics approval and consent to participate: The study protocol was approved by the Ethics Committee of the Hospital de Clínicas de Porto Alegre (HCPA), and free and informed consent was obtained from each participant's parents or guardians (150143/2015).

Availability of data and materials: The datasets used and/or analysed during the current study are available from the corresponding author on reasonable request.

Consent for publication: Not applicable.

Funding: Not applicable.

Competing interests: The authors declare that they have no competing interests.

Authors' contribution: M.C. conducted extraction, analyzed and interpreted of data, wrote the main manuscript text, reviewed the manuscript, prepared figures and tables, approved the submitted version, 
agreed to be personally accountable for the author's own contributions. C.S. conducted data extraction, prepared figures and tables, reviewed the manuscript, approved the submitted version, agreed to be personally accountable for the author's own contributions. G.M. wrote the main manuscript text, reviewed the manuscript, approved the submitted version, agreed to be personally accountable for the author's own contributions. G.C.B. reviewed the manuscript, approved the submitted version, agreed to be personally accountable for the author's own contributions. T.H.R. reviewed the manuscript, approved the submitted version, agreed to be personally accountable for the author's own contributions. P.J.C.M. analyzed and interpreted of data, wrote the main manuscript text, reviewed the manuscript, approved the submitted version, agreed to be personally accountable for the author's own contributions. P.M.E.R. analyzed and interpreted of data, wrote the main manuscript text, reviewed the manuscript, prepared figures and tables, approved the submitted version, agreed to be personally accountable for the author's own contributions. All authors read and approved the final manuscript.

Acknowledge: Not applicable.

\section{References}

1. Okuro RT, de Oliveira Ribeiro MA, Ribeiro JD, Minsky RC, Schivinski Cl. Alternative Indexes to Estimate the Functional Capacity From the 6-Minute Walk Test in Children and Adolescents With Cystic Fibrosis. Respir Care. 2017.

2. Rovedder PM, Flores J, Ziegler B, Casarotto F, Jaques P, Barreto SS, et al. Exercise programme in patients with cystic fibrosis: a randomized controlled trial. Respir Med. 2014;108(8):1134-40.

3. Burtin C, Van Remoortel H, Vrijsen B, Langer D, Colpaert K, Gosselink R, et al. Impact of exacerbations of cystic fibrosis on muscle strength. Respir Res. 2013;14:46.

4. Hebestreit $H$, Schmid K, Kieser S, Junge S, Ballmann M, Roth K, et al. Quality of life is associated with physical activity and fitness in cystic fibrosis. BMC Pulm Med. 2014;14:26.

5. Legroux-Gerot I, Leroy S, Prudhomme C, Perez T, Flipo RM, Wallaert B, et al. Bone loss in adults with cystic fibrosis: prevalence, associated factors, and usefulness of biological markers. Joint Bone Spine. 2012;79(1):73-7.

6. Beets MW, Huberty J, Beighle A. Physical activity of children attending afterschool programs: research- and practice-based implications. Am J Prev Med. 2012;42(2):180-4.

7. Rush E, Coppinger T, Obolonkin V, Hinckson E, McGrath L, McLennan S, et al. Use of pedometers to identify less active children and time spent in moderate to vigorous physical activity in the school setting. J Sci Med Sport. 2012;15(3):226-30.

8. Quon BS, Patrick DL, Edwards TC, Aitken ML, Gibson RL, Genatossio A, et al. Feasibility of using pedometers to measure daily step counts in cystic fibrosis and an assessment of its responsiveness to changes in health state. J Cyst Fibros. 2012;11(3):216-22.

9. Craig CL, Cameron C, Tudor-Locke C. CANPLAY pedometer normative reference data for 21,271 children and 12,956 adolescents. Med Sci Sports Exerc. 2013;45(1):123-9. 
10. Elborn JS, Hodson M, Bertram C. Implementation of European standards of care for cystic fibrosis provision of care. J Cyst Fibros. 2009;8(5):348-55.

11. Tremblay MS, LeBlanc AG, Janssen I, Kho ME, Hicks A, Murumets K, et al. Canadian sedentary behaviour guidelines for children and youth. Applied Physiology, Nutrition, and Metabolism. 2011;36(1):59-64.

12. McNamara E, Hudson Z, Taylor SJ. Measuring activity levels of young people: the validity of pedometers. Br Med Bull. 2010;95:121-37.

13. Tudor-Locke C, Burkett L, Reis JP, Ainsworth BE, Macera CA, Wilson DK. How many days of pedometer monitoring predict weekly physical activity in adults? Prev Med. 2005;40(3):293-8.

14. Singh SJ, Morgan MD, Scott S, Walters D, Hardman AE. Development of a shuttle walking test of disability in patients with chronic airways obstruction. Thorax. 1992;47(12):1019-24.

15. Borg GA. Psychophysical bases of perceived exertion. Med Sci Sports Exerc. 1982;14(5):377-81.

16. Wild LB, Dias AS, Fischer GB, Rech DR. Pulmonary function tests in asthmatic children and adolescents: Comparison between a microspirometer and a conventional spirometer. J Bras Pneumol. 2005;31(2):97-102.

17. Quanjer PH, Stanojevic S, Cole TJ, Baur X, Hall GL, Culver BH, et al. Multi-ethnic reference values for spirometry for the 3-95-yr age range: the global lung function 2012 equations. Eur Respir J. 2012;40(6):1324-43.

18. Graham BL, Steenbruggen I, Miller MR, Barjaktarevic IZ, Cooper BG, Hall GL, Hallstrand TS, Kaminsky DA, McCarthy K, McCormack MC, Oropez CE, Rosenfeld M, Stanojevic S, Swanney MP, Thompson BR. Standardization of Spirometry 2019 Update. An Official American Thoracic Society and European Respiratory Society Technical Statement. Am J Respir Crit Care Med. 2019;200(8):70-88.

19. Santos $\mathrm{Cl}$, Ribeiro JD, Ribeiro AF, Hessel G. Critical analysis of scoring systems used in the assessment of Cystic Fibrosis severity: State of the art. J Bras Pneumol. 2004;30(3):286-98.

20. Cabral LGdA, Costa FFd, Liparotti JR. Preliminary validation of the physical activity section of the Previous Day Physical Activity and Food Consumption Questionnaire. 2011.

21. Tudor-Locke C, McClain JJ, Hart TL, Sisson SB, Washington TL. Expected values for pedometerdetermined physical activity in youth. Res Q Exerc Sport. 2009;80(2):164-74.

22. Boucher GP, Lands LC, Hay JA, Hornby L. Activity levels and the relationship to lung function and nutritional status in children with cystic fibrosis. Am J Phys Med Rehabil. 1997;76(4):311-5.

23. Sahlberg M, Svantesson U, Magnusson Thomas E, Andersson BA, Saltin B, Strandvik B. Muscular strength after different types of training in physically active patients with cystic fibrosis. Scand $\mathrm{J}$ Med Sci Sports. 2008;18(6):756-64.

24. Troosters T, Langer D, Vrijsen B, Segers J, Wouters K, Janssens W, et al. Skeletal muscle weakness, exercise tolerance and physical activity in adults with cystic fibrosis. Eur Respir J. 2009;33(1):99-106.

25. Mackintosh KA, Ridgers ND, Evans RE, McNarry MA. Physical Activity and Sedentary Time Patterns in Children and Adolescents With Cystic Fibrosis and Age- and Sex-Matched Healthy Controls. J Phys 
Act Health. 2018;15(2):82-8.

26. Tudor-Locke C, Craig CL, Beets MW, Belton S, Cardon GM, Duncan S, et al. How many steps/day are enough? for children and adolescents. Int J Behav Nutr Phys Act. 2011;8:78.

27. Prasad SA, Cerny FJ. Factors that influence adherence to exercise and their effectiveness: application to cystic fibrosis. Pediatr Pulmonol. 2002;34(1):66-72.

28. Selvadurai HC, Blimkie CJ, Cooper PJ, Mellis CM, Van Asperen PP. Gender differences in habitual activity in children with cystic fibrosis. Arch Dis Child. 2004;89(10):928-33.

\section{Figures}

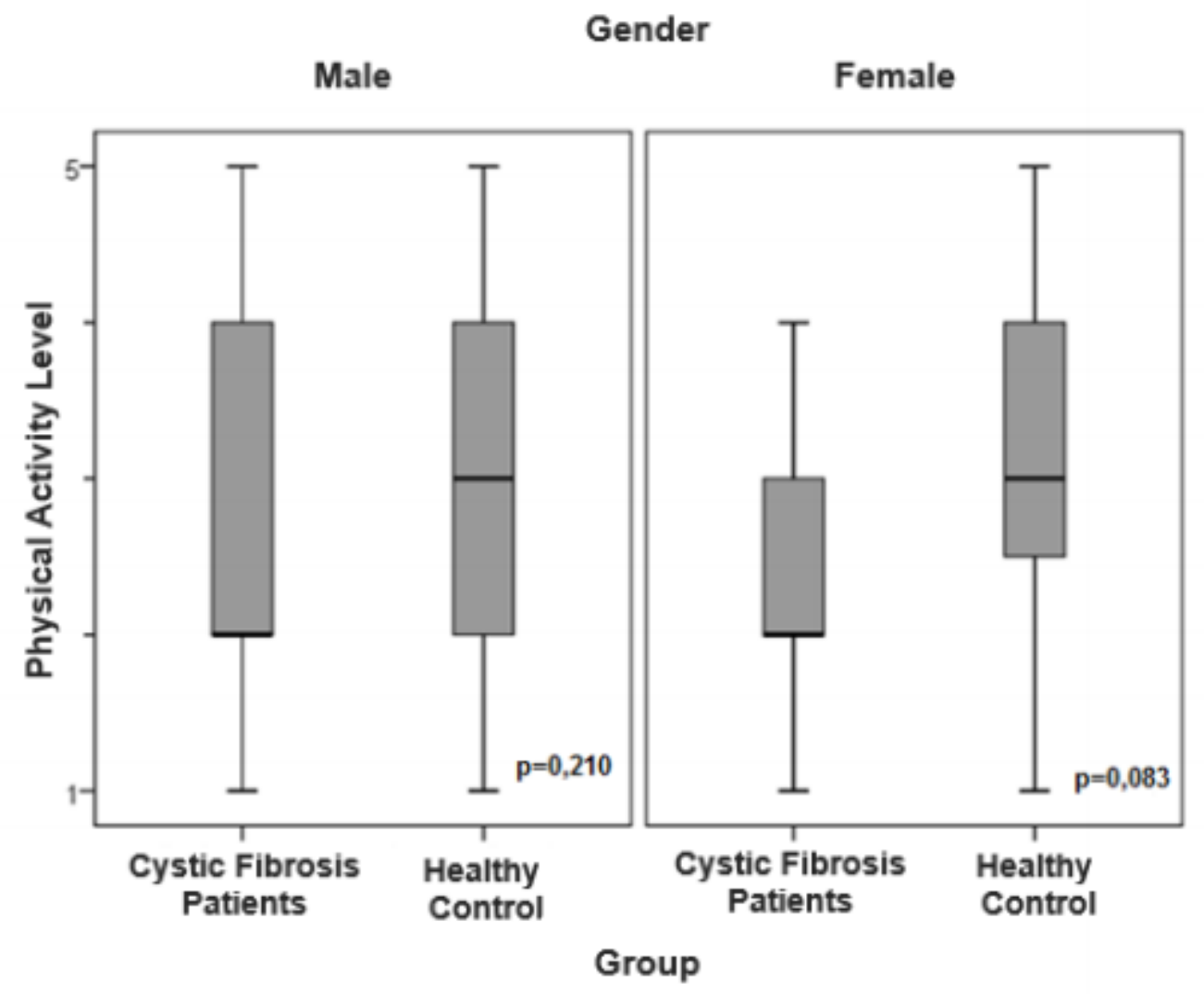

Figure 1

Comparison of level of daily physical activity stratified by gender in the patient and control groups. 


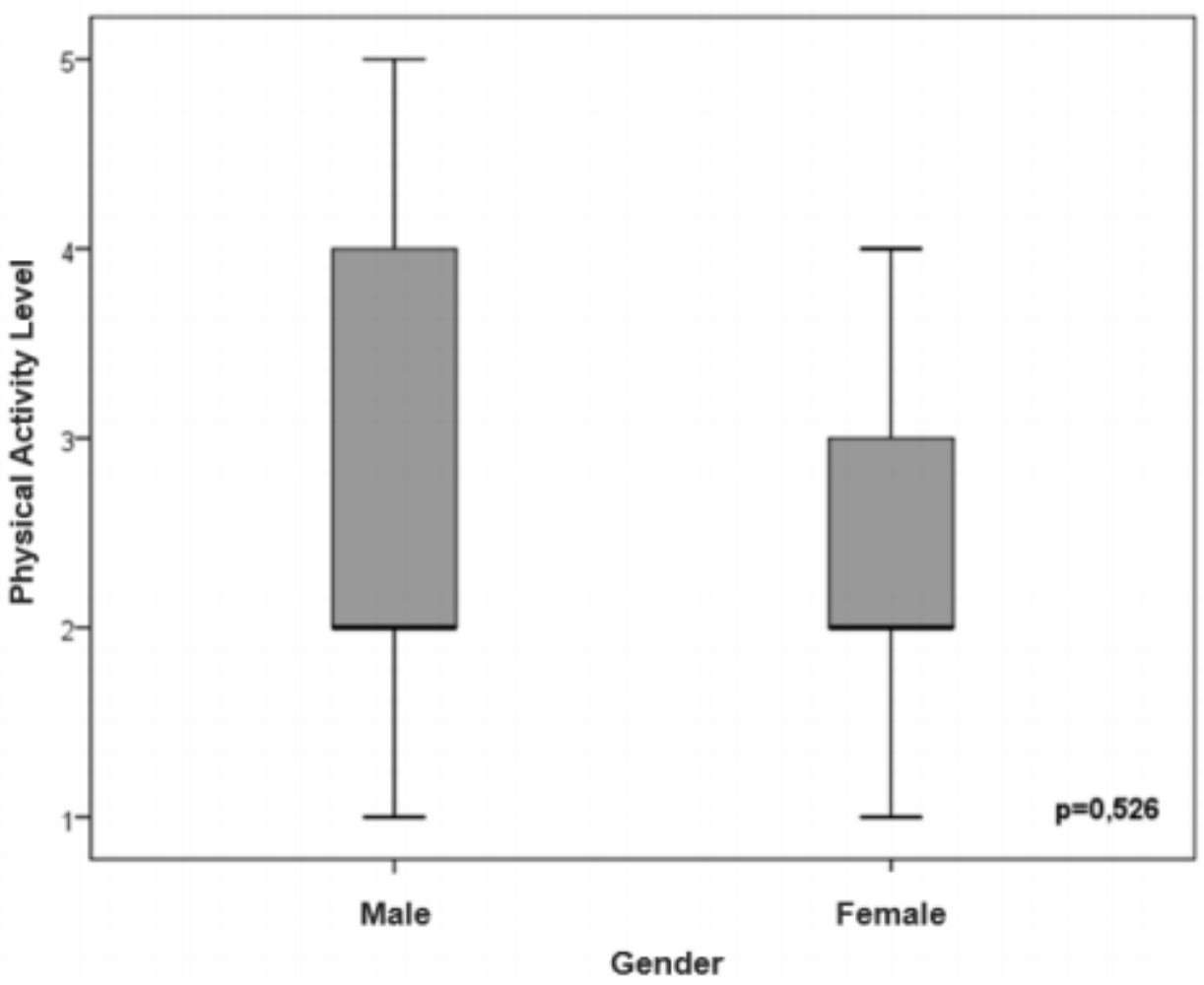

Figure 2

Comparison of level of daily physical activity between genders in CF patients. 